\title{
Comparison of left ventricular geometry after HeartMate II and HeartWare left ventricular assist device implantation
}

\author{
Morteza Tavakkoli Hosseini ${ }^{1 *}$, Aron Frederik Popov ${ }^{1,2^{*}+}$, Andre Ruediger Simon ${ }^{1}$, Mohamed Amrani ${ }^{1}$ \\ and Toufan Bahrami ${ }^{1}$
}

\begin{abstract}
Background: HeartMate II (HM II) and HeartWare (HW) Left Ventricular Assist Devices have been successfully used in end-stage heart failure patients as a bridge to transplantation, recovery, or decision. We set out to compare their effect in off-loading the left ventricle and its geometry.

Methods: The left ventricular end diastolic (LVEDD) and end systolic (LVESD) diameters were compared between first time HM II $(n=25)$ and HW implantations $(n=24)$ before and after the operation at 1,3 , and 6 months. A p value of less than 0.05 was considered as significant.

Results: Post-operative LVEDD and LVESD at 1, 3, and 6 months were significantly reduced in comparison with preoperative values in both HM II and HW groups. No significant difference was found comparing HM II and HW groups together before and after the operation.

Conclusions: Our study shows that both HM II and HW can significantly reduce the left ventricular systolic and diastolic dimensions and off-load the left ventricle. The miniaturized nature of HW does not affect its performance and it could be as effective as HM II.
\end{abstract}

Keywords: Cardiomyopathy, Heart failure, Ventricular assist device, Echocardiography

\section{Background}

Mechanical circulatory support for patients with advanced heart failure has evolved considerably during the past 30 years and is now the standard therapy at many medical centers worldwide [1]. Ventricular Assist Devices (VAD) have been mainly used as a bridge to transplantation. Nowadays, as a result of donor shortage and the success of the newer devices, they are also considered as a bridge to recovery or a bridge to decision [2].

In the last decade, the smaller second generation continuous-flow assist devices have successfully replaced their first generation pulsatile predecessors. They have proved to be more reliable, smaller in size, and have

\footnotetext{
*Correspondence: morteza.tavakkoli@gmail.com;

Popov@med.uni-goettingen.de

${ }^{\dagger}$ Equal contributors

'Department of Cardiothoracic Surgery and Transplantation Harefield

Hospital, Harefield, London, UK

Full list of author information is available at the end of the article
}

lower rates of adverse events (infection, bleeding, stroke, and device failure). The most common second generation devices currently used are HeartMate II (Thortec Inc.) [3], Micromed Debakey [4], Berlin Heart Incor (Berlin Heart AG) [5], and Jarvik 2000 (Jarvik Heart Inc.) [6]. HeartMate II is the most successful and widely used second generation VAD.

Another recent addition to this family is HeartWare VAD (HeartWare Inc). It is a miniaturized centrifugal blood pump that could be placed intra-pericardially, thereby avoiding abdominal surgery and pump pocket formation. It has proved to provide satisfactory long term survival with excellent quality of life, low rate of adverse events and feasibility for implantation via minimally invasive incisions [7-10]. There has been a debate if the miniaturized nature of the pump could affect its effect on off-loading of the left ventricle, in comparison with the bigger second generation VAD systems. We set out to compare the effect of HeartWare (HW) and

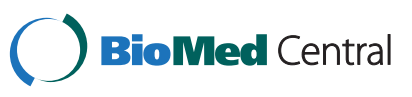


Table 1 Pre-operative patients' demographics

\begin{tabular}{lllll}
\hline & Number & Male & Female & Age \\
\hline HeartMate II & 25 & $19(76 \%)$ & $6(24 \%)$ & $41.32+/-12.29$ \\
HeartWare & 24 & $19(79 \%)$ & $5(21 \%)$ & $50.29+/-11.91$ \\
\hline
\end{tabular}

HeartMate II (HM II) VAD systems in off-loading the left ventricle and its geometry.

\section{Methods}

First time HM II and HW implantations for Dilated Cardio-Myopathy performed at Harefield Hospital from April 2008 to October 2010 were included in this study. Pre-operative and post-operative (first month and then three-monthly) echocardiography is performed at Harefield Hospital as a routine follow up procedure for all patients with a VAD implantation. Echocardiography data is inclusive of the left ventricular systolic diameter and the left ventricular diastolic diameter at baseline VAD pump speed (9600 rpm for HM II and $2800 \mathrm{rpm}$ for $\mathrm{HW}$ ).

This data was part of Harefield Hospital post VAD surgery data collection and outcome evaluation. The study was categorized as a Service Evaluation by the Ethical Committee and required no need for ethical approval.

Fisher's exact test was used for comparing the demographic factors, and the mortality. Pre-operative left ventricular parameters were compared with the postoperative left ventricular parameters at 1,3 , and 6 months after the operation, using Analysis of Variance (ANOVA) test. A p value of less than 0.05 was considered as significant. The study design was a retrospective review of the prospectively collected data.

\section{Results}

HM II and HW groups contained 25 and 24 patients respectively. All patients had a history of Dilated CardioMyopathy with NYHA class 4 symptoms. Table 1 shows the demographics of the two groups. The mean age in HW group (50.29) was significantly higher than the mean age in HM II group (41.32). Six months mortality in HM II and HW groups were 9 (36\%) and 4 (16\%) respectively, with no significant difference. Table 2 shows the systolic and diastolic left ventricular diameters before and after VAD implantation. There was a significant difference between pre-operative and post-operative left ventricular diameters in each group. No significant difference was noticed in post-operative left ventricular diameters of each group. When comparing HM II and HW groups together, there was no significant difference in the pre-operative or post-operative left ventricular diameters in between the two groups.

\section{Discussion}

Ventricular Assist Device systems have revolutionized the management of end stage heart failure. They are used as a bridge to transplantation, recovery, or decision $[1,2,7-9,11]$. There is a growing trend towards the use of smaller and more compact devices, with the aim of avoiding abdominal surgery, pump pocket formation, and reduction of the adverse events. Smaller devices also provide the chance for minimally invasive incisions, instead of a conventional median sternotomy [10]. HM II is the most successful and widely used second generation VAD system [1-3]. Echocardiographic studies show that HM II reduces the left ventricular end-diastolic dimension by $21 \%$ and $35 \%$, one week and 4 months after VAD implantation respectively [12]. It has been quoted that patients with a relatively small left ventricular end diastolic diameters $(<63 \mathrm{~mm})$ have a significantly higher risk for in-hospital mortality [13]. Maybaum et al. reported in their study for cardiac recovery that HeartMate, Novacor, and Debakey VAD systems significantly decrease the left ventricular end diastolic diameters at $1,2,3$, and 4 months after VAD implantation [14]. In the initial clinical experience with HW, no comparison was made between the pre-operative and

Table 2 Pre and post VAD implantation left ventricular diameters

\begin{tabular}{lllll}
\hline & Pre operative & 1 Month & 3 Months & 6 Months \\
\hline HM II LVEDD mm & $72.8+/-9.3$ & $54.7+/-16.7$ & $54.1+/-14.5$ & $56.5+/-13.7$ \\
HW LVEDD mm & $68.9+/-10.1$ & $57.5+/-10.4$ & $57.9+/-11.2$ & $59.3+/-8.2$ \\
HM II LVEDD\% & $* * *$ & $-25.1+/-21.0$ & $-27.3+/-17.1$ & $-24.7+/-15.4$ \\
HW LVEDD\% & $* * *$ & $-17.3+/-13.0$ & $-17.7+/-16.5$ & $-14.9+/-12.3$ \\
HM II LVESD mm & $66.0+/-9.3$ & $47.0+/-15.8$ & $44.5+/-16.2$ & $45.9+/-15.3$ \\
HW LVESD mm & $59.8+/-10.7$ & $51.1+/-12.5$ & $50.1+/-11.7$ & $50.6+/-8.5$ \\
HM II LVESD\% & $* * *$ & $-28.4+/-21.9$ & $-34.2+/-20.0$ & $-32.9+/-18.9$ \\
HW LVESD\% & $* * *$ & $-17.0+/-17.1$ & $-19.5+/-19.7$ & $-18.3+/-15.2$ \\
\hline
\end{tabular}

HM II: HeartMate II; HW: HeartWare; LVEDD: Left Ventricular End Diastolic Diameter; LVESD: Left Ventricular End Systolic Diameter; LVEDD\%: Left Ventricular End Diastolic Diameter change compared to each patient's pre-operative value; LVESD\%: Left Ventricular End Systolic Diameter change compared to each patient's pre-operative value. 
post-operative left ventricular dimensions [7,8]. Our study confirms that HW significantly reduces the left ventricular systolic and diastolic dimensions and off-load the left ventricle in the short and long term. The miniaturized nature of the pump does not affect its performance, as no significant difference was noticed while comparing HW and HM II. We did not checked for the left ventricular dimensions at partial pump support/ pump off status, as the aim of the study was not to check for myocardial recovery. Myocardial recovery is a debatable discussion in the current era with so many proponents and opponents [11,14]. Groups were not sub-analyzed based on the etiology of Dilated CardioMyopathy. Ethiology affects the outcome and the potential for recovery, but not the mechanical ability of the device in off-loading the left ventricle. So far, the implantation of smaller VAD systems via median sternotomy or minimally invasive incisions, has proved to be successful with satsifactory clinical and echocardiographic results $[7,8,10]$.

\section{Conclusions}

Our study shows that both HM II and HW can significantly reduce the left ventricular systolic and diastolic dimensions and off-load the left ventricle. The miniaturized nature of HW does not affect its performance and it could be as effective as HM II.

\section{Competing interest}

The authors declare that they have no competing interests.

\section{Authors' contributions}

MTH and AFP designed the study, collected the data, wrote and revised the manuscript. MA, and ARS carried out the surgical procedures, and revised the manuscript. TB carried out the surgical procedures, co-wrote and revised the manuscript, supervised and lead the study. All authors read and approved the final manuscript.

\section{Author details}

'Department of Cardiothoracic Surgery and Transplantation Harefield Hospital, Harefield, London, UK. ²Department of Thoracic Cardiovascular Surgery, University of Göttingen, Göttingen, Germany.

Received: 27 September 2012 Accepted: 22 February 2013

Published: 28 February 2013

\section{References}

1. Slaughter MS, Pagani FD, Rogers JG, Miller LW, Sun B, Russell SD, et al: Clinical management of continuous-flow left ventricular assist devices in advanced heart failure. J Heart Lung Transp/ 2010, 29:1-39.

2. Lahpor JR: State of the art: implantable ventricular assist devices. Curr Opin Organ Transp/ 2009, 14:554-559.

3. Miller LW, Pagani FD, Russell SD, John R, Boyle AJ, Aaronson KD, et al: Use of a continuous-flow device in patients awaiting heart transplantation. N Engl J Med 2007, 357:885-896.

4. Goldstein DJ, Zucker M, Arroyo L, Baran D, McCarthy PM, Loebe M, et al: Safety and feasibility trial of the MicroMed DeBakey ventricular assist device as a bridge to transplantation. J Am Coll Cardiol 2005, 45:962-963.

5. Hetzer $R$, Weng $Y$, Potapov EV, Pasic M, Drews $T$, Jurmann $M$, et al: First experiences with a novel magnetically suspended axial flow left ventricular assist device. Eur J Cardiothorac Surg 2004, 25:964-970.

6. Macris MP, Myers TJ, Jarvik R, Robinson JL, Fuqua JM, Parnis SM, et al: In vivo evaluation of an intraventricular electric axial flow pump for left ventricular assistance. ASAIO J 1994, 40:719-722.
7. Wieselthaler GMO, Driscoll G, Jansz P, Khaghani A, Strueber M, HVAD Clinical Investigators: Initial clinical experience with a novel left ventricular assist device with a magnetically levitated rotor in a multi-institutional trial. J Heart Lung Transplant 2010, 29:1218-25.

8. Strueber M, O'Driscoll G, Jansz P, Khaghani A, Levy WC, Wieselthaler GM, et al: Multicenter evaluation of an intrapericardial left ventricular assist system. J Am Coll Cardiol 2011, 57:1375-1382.

9. Popov AF, Hosseini MT, Zych B, Mohite P, Hards R, Krueger H, Bahrami T, Amrani $M$, Simon AR: Clinical experience with HeartWare left ventricular assist device in patients with end-stage heart failure. Ann Thorac Surg 2012, 93:810-815

10. Popov AF, Hosseini MT, Zych B, Simon AR, Bahrami T: HeartWare left ventricular assist device implantation through bilateral anterior thoracotomy. Ann Thorac Surg 2012, 93:674-676.

11. Birks EJ, George RS, Hedger M, Bahrami T, Wilton P, Bowles CT, et al: Reversal of severe heart failure with a continuous-flow left ventricular assist device and pharmacological therapy: a prospective study. Circulation 2011, 123:381-390.

12. Weiss RM, Kerber RE, Goerbig-Campbell JL, Davis MK, Cabuay BM, Ashrith G, et al: The impact of prolonged rotary ventricular assist device support upon ventricular geometry and flow kinetics. J Am Soc Echocardiogr 2011, 24:149-156.

13. Topilsky Y, Oh JK, Shah DK, Boilson BA, Schirger JA, Kushwaha SS, et al: Echocardiographic predictors of adverse outcomes after continuous left ventricular assist device implantation. JACC CardiovasC Imaging 2011, 4:211-222.

14. Maybaum S, Mancini D, Xydas S, Starling RC, Aaronson K, Pagani FD, et al: Cardiac improvement during mechanical circulatory support: a prospective multicenter study of the LVAD working group. Circulation 2007, 115:2497-2505.

doi:10.1186/1749-8090-8-31

Cite this article as: Hosseini et al: Comparison of left ventricular geometry after HeartMate II and HeartWare left ventricular assist device implantation. Journal of Cardiothoracic Surgery 2013 8:31.

\section{Submit your next manuscript to BioMed Central and take full advantage of:}

- Convenient online submission

- Thorough peer review

- No space constraints or color figure charges

- Immediate publication on acceptance

- Inclusion in PubMed, CAS, Scopus and Google Scholar

- Research which is freely available for redistribution 